\title{
MISOGINIA Y VIOLENCIA HACIA LAS MUJERES: DIMENSIONES SIMBÓLICAS DEL GÉNERO Y DEL PATRIARCADO*
}

\author{
MISOGYNY AND VIOLENCE AGAINST WOMEN: \\ THE SYMBOLIC DIMENSIONS OF GENDER AND PATRIARCHY
}

\section{MACARENA TRUJILLO CRISTOFFANINI**}

Resumen: Este artículo analiza críticamente la presencia de la misoginia y de la violencia ejercida hacia las mujeres en la construcción simbólica de dos figuras femeninas presentes en mitos cosmogónicos de gran valor para la cultura occidental: Pandora y Eva. La relevancia de este análisis radica en que estas narraciones habitan aquellos relatos que están en la génesis de la diferenciación sexista entre hombres y mujeres. De manera específica, se establece que en los relatos de Pandora y de Eva emergen dos elementos cardinales que reproducen la violencia simbólica hacia las mujeres: la devaluación femenina y el imperativo de ser para otro. Por último, se declara que visibilizar los elementos de violencia simbólica que subyacen en estas narraciones es un ejercicio ineludible cuando se busca desentrañar las conexiones entre pasado y presente inscritas en las expresiones culturales que naturalizan la violencia hacia las mujeres.

Palabras clave: Violencia de género, violencia simbólica, mitos cosmogónicos, Pandora, Eva.

AвSTRACT: This article critically analyzes the presence of misogyny and violence against women in the symbolic construction of two female figures present in cosmogonic myths of great value to Western culture: Pandora and Eve. The relevance of this analysis resides in the character of these narratives as stories that recount the genesis of sexist differentiation between men and women. Specifically, this article maintains that two primary elements emerge from the myths of Pandora and Eve and contribute to the reproduction of symbolic violence towards women: feminine devaluation and the imperative of being for another. The article concludes that visualizing the underlying elements of symbolic violence in these narratives is an essential exercise in the effort to

* Este artículo ha sido financiado por CONICYT, FONDECYT de Iniciación N 11170484 , del cual su autora es Investigadora Responsable.

** Doctora en Sociología. Académica de la Facultad de Ciencias Sociales, Universidad de Playa Ancha, Valparaíso, Chile. Correo electrónico: macarenatrujilloc@gmail.com. 
unravel the connections between past and present inscribed in cultural expressions that naturalize violence against women.

KeYwORDs: Gender violence, symbolic violence, cosmogonic myths, Pandora, Eve.

Recibido: 12.04.18. Aceptado: 20.03.19.

\section{INTRODUCCIÓN}

E N LAS DIVERSAS sociedades se elaboran mitos cosmogónicos o fundacionales, cuyo fin es explicar los orígenes del mundo. En dichos relatos habitan configuraciones sobre el orden y las jerarquías sociales, donde los dispositivos de poder juegan un papel fundamental al enmarcar estos saberes -inscritos en los mitos fundacionales- como únicos y legítimos (Eliade, 2000; Martínez Fernández, 1996). De este modo, tales mitos constituyen relatos que fundamentan un tipo de verdad absoluta en la que "se cuenta cómo se efectuó algo, cómo comenzó a ser” (Eliade, 1998, p. 72).

En los mitos en que se representan las historias de Pandora y de Eva emergen narrativas fundacionales del nacimiento de la humanidad que se yerguen desde una determinada perspectiva cultural. No obstante, no solo se narra el origen de lo humano como tal, sino, también, se vislumbra la génesis de las distinciones entre lo masculino y lo femenino. Desde un análisis enunciado en clave de género, se puede proyectar cómo, desde esta distinción, se justifica la supuesta naturaleza inferior de las mujeres y, con ello, se naturaliza una construcción misógina de la realidad (Tubert, 1991; Montecino, 1997); o, lo que es equivalente, una estructura de poder/conocimiento basada en una lógica de desvalorización y de desprecio de lo femenino, que se traduce en un conjunto de creencias y conductas negativas hacia las mujeres como colectivo (Ferrer y Bosch, 2000).

El dispositivo que instala la misoginia en la lectura social de la realidad es un componente clave de las sociedades patriarcales, ya que está directamente relacionado con creencias sesgadas sobre mujeres y varones, con aseveraciones sobre la desigualdad natural entre ambos sexos y, consecuentemente, con la consideración de la violencia de género como práctica culturalmente aceptable (Alberdi y Matas, 2002; Bosch, Ferrer y Gili, 1999). De acuerdo con estas premisas, aquí se afirma que las creencias que legitiman la misoginia pueden considerarse como un factor que, en parte, explica la violencia hacia las mujeres, así como el mantenimiento y la naturalización de estas conductas en la sociedad (Bosch y Ferrer, 2003). 
Sobre esta base, el objetivo de este trabajo es analizar, desde una mirada crítica, la producción de discursos misóginos en las narraciones de Pandora y de Eva, ya que se afirma que estos discursos son funcionales a las sociedades patriarcales y son parte de la legitimación de la violencia hacia las mujeres en sus dimensiones tanto simbólicas como materiales.

Con este propósito, en la primera parte de este texto se describen los mitos de Eva y de Pandora, y se enfatizan aquellos elementos que transmiten expresiones sexistas sobre los orígenes de la humanidad. En la segunda parte, se destaca el papel de los mitos fundacionales en la legitimación simbólica de las relaciones sociales patriarcales y la consecuente construcción del sistema sexo-género. En el tercer apartado, se analizan las dimensiones de violencia y misoginia que se pueden desprender de los mitos abordados. Por último, en las reflexiones finales, se subraya que abordar críticamente el papel de estos mitos abre una posibilidad de visibilizar el peso de entramados simbólicos que, a fin de cuentas, sustentan la conservación del patriarcado occidental moderno. En suma, el análisis de los mitos implicará transformar el sentido del orden patriarcal desde la teoría y la crítica feminista, potenciando, así, una lectura no androcéntrica de la realidad social.

\section{LOS MITOS DE PANDORA Y DE EVA}

La narración de Pandora está contenida en el mito de Prometeo del que hace eco Hesíodo en la Teogonía y en el poema Los trabajos y los días (circa 700 a.C.). El mito de Prometeo "se relaciona con la creación del hombre, y [con] el surgimiento de la civilización” (Martínez Fernández, 1996, p. 19). Según Graves (1967), este mito representa una disputa donde se discute sobre qué partes de un toro sacrificado corresponde entregar a los hombres y qué partes deben ser reservadas para los dioses. Con el objetivo de resolver tal disyuntiva -dice el mito-, se invitó a Prometeo a actuar de árbitro. Dado que el titán deseaba beneficiar a los humanos, dividió los restos del animal en dos porciones: en la primera, ocultó la carne bajo los intestinos para que pareciera menos apetitosa; $y$, en la segunda, cubrió los huesos bajo una llamativa capa de grasa. Al saberse engañado -continúa el relato-, Zeus decidió castigar a los humanos apoderándose de la fuerza del fuego; sin embargo, Prometeo quiso nuevamente burlarse del dios robándole la llama para beneficio de los hombres. El hecho irritó aún más a Zeus, quien impuso un severo castigo a Prometeo: fue atado al centro de una columna donde un águila le roía el hígado; peor aún, cada noche, el órgano roído se 
regeneraba y el ave rapaz prolongaba un suplicio infinito. Pero este no fue el único castigo que Zeus impuso a Prometeo:

Te crees el más sagaz de todos y te ríes, satisfecho por haber robado el fuego y engañado mi ánimo. Pero eso no será la mayor de las desgracias para ti y para los hombres. En sustitución del fuego, mandaré a los mortales un mal, al que todos, sin embargo, halagarán amorosamente como si no se tratara de una desgracia. (Hesíodo, 1993, p. 45)

La desgracia a la que se refiere Hesíodo es Pandora, la primera mujer de la humanidad "a la que Zeus había hecho tan tonta, malévola y haragana como bella, la primera de una larga casta de mujeres como ella" (Graves, 1967, p. 166). Con estas palabras, Hesíodo relata cómo Zeus envió a Hefesto a mezclar agua con tierra para formar una virgen que destacara por su hermosura, y cómo fue Atenea a quien le encomendó la tarea de enseñarle "las labores de mujer"; Hesíodo insiste:

A Afrodita se le pidió que ungiera su frente de la gracia, y le comunicara el doloroso deseo, además de la inquietud que destroza los miembros. Asimismo, mandó a Hermes, el mensajero, matador de Argos, que inspirara la impudicia y la falsedad de la bella virgen. (Hesíodo, 1993, p. 46)

Y de este modo se convierte a Pandora en un castigo, pues ella se vislumbra como "la suerte desfavorable y que, como la mayor de las desgracias, fuera el azote de los mortales" (Hesíodo, 1993, p. 46). Una vez creada, Zeus envía a Pandora donde Prometeo, junto con un ánfora que jamás debía abrir. El titán, atento a las estrategias de Zeus, no aceptó a Pandora como esposa, pero, su hermano Epimeteo -prendado de la belleza de la mujer- sí lo hizo ${ }^{1}$. Una vez aceptada por Epimeteo, Pandora abre la caja que Zeus le había entregado y, desde su interior, brotan todos los males del mundo, hasta entonces, desconocidos por el hombre. En palabras de Hesíodo:

La raza humana vivía antes de eso en la tierra al amparo y abrigo de todo mal, de la dura fatiga y de las dolorosas enfermedades que acarrean la muerte a los hombres. Pero la mujer Pandora, al levantar con sus propias manos la ancha tapa del ánfora que las contenía, derramó y esparció sobre los hombres los más nefastos pesares. Solo la Esperanza se quedó en el interior de la infranqueable prisión, sin rebasar los bordes

\footnotetext{
${ }^{1}$ Precisamente, el nombre Epimeteo quiere decir "de inteligencia tardía”.
} 
de la jarra, porque Pandora había puesto nuevamente la tapa. (Hesíodo, 1993, p. 47) $)^{2}$

Además, y de acuerdo con Molas Font (2006), se puede afirmar que, en el mito de Prometeo, Hesíodo construye un discurso misógino que desvaloriza a las mujeres desde el instante de su creación. Incluso más, este discurso obedece a una matriz de poder patriarcal que justifica, cuando no naturaliza, la infravaloración de las mujeres.

El mito de Eva, por su parte, está presente en los libros I, II y III del Génesis bíblico. En esta narración se describe el nacimiento del primer hombre y de la primera mujer según la cosmovisión judeo-cristiana. En ella se señala que, una vez que Dios creó a Adán, pensó: "no es bueno que el hombre esté solo, voy a hacerle una ayuda proporcionada a él" (Génesis, 1968, p. 31). De este modo -explica el mito-, Dios creó animales, ganados, aves del cielo y bestias del campo, pero, entre todos ellos, observó que el hombre no tenía semejantes. Así, Dios hizo caer al hombre en un profundo sopor, le quitó una costilla y, a partir de ella, formó a la mujer, denominada en primera instancia varona, porque del varón había sido tomada ${ }^{3}$. Posteriormente, el mito narra cómo esta mujer cayó en el engaño de la serpiente y comió del fruto prohibido, y cómo ella persuadió a Adán a comerlo también. Tras morder la manzana -se lee en el Génesis-, la pareja advirtió su desnudez y sintió, por vez primera, vergüenza. Por este hecho, Yavé notó que Adán y Eva habían probado el fruto del árbol de la ciencia del bien y del mal. El castigo divino les cayó encima y Yavé reprendió con severidad a Adán:

Por haber escuchado a tu mujer comiendo del árbol que te prohibí comer, diciéndote que no comas de él. Por ti, será maldita la tierra. Con trabajo comerás de ella todo el tiempo de tu vida; te dará espinas y abrojos. Y comerás de las hierbas del campo. Con el sudor de tu rostro comerás el pan. Hasta que vuelvas a la tierra. Ya que polvo eres y polvo serás. (Génesis, 1968, p. 32)

\footnotetext{
${ }^{2}$ Es interesante tener en cuenta que de esta narración proviene el popular refrán "la esperanza es lo último que se pierde", ejemplo que da cuenta de la presencia cotidiana y soterrada de los mitos.

${ }^{3}$ Es importante señalar que hay alguna diferencia en el relato narrado en el libro del Génesis, I y II. En el primero se señala que después de crear a los animales, Dios crea al ser humano, al hombre y a la mujer como finalización de su obra. Es en el libro II en el que se destaca que la mujer ha sido creada con posterioridad al hombre, utilizando una costilla. Aun así, a pesar de existir dos versiones sobre el origen de la mujer, es esta última la que ha calado con mayor profundidad en los imaginarios sociales de género.
} 
Consecutivamente, Yavé se dirigió a la mujer y sentenció: "multiplicarás el trabajo de tus preñeces. Parirás con dolor los hijos y buscarás con ardor a tu marido que te dominará" (Génesis, 1968, p. 32). Luego, ambos fueron expulsados del paraíso.

De acuerdo con lo anterior, se puede analizar cómo, en este relato, emergen dimensiones simbólicas vinculadas a la desigualdad de género. Así, se constituye la figura de Eva como la de aquella mujer que, además de empujar al varón al pecado, es culpable de que la humanidad abandone el paraíso y vivencie males inimaginables. A su vez, desde la lectura de Lagarde (1997), la acción de Eva en el paraíso subvierte un primer orden masculino cuya restitución exige el castigo de la mujer: "Parirás con dolor". Con este sino, el mito de Eva traza la equivalencia entre lo femenino y las características sancionadas como negativas. Tal como señala Lagarde: con la transgresión y el consecuente castigo de Eva, "se logró la representación simbólica de todas y cada una de las mujeres: por su desobediencia erótica e intelectual son la encarnación del mal y están destinadas a ser culpables y a sufrir para pagar su culpa" (p. 322). Por ello, a partir de este castigo, se erige simbólicamente el colectivo de las mujeres y, además, se proyecta la "sexualidad-natural-procreadora" como elemento central de la identidad femenina patriarcal que pervive hasta la actualidad en las mujeres (Trujillo \& Almeda, 2017).

En este contexto, desde una lectura feminista -es decir desde una mirada no sexista y no androcéntrica de la realidad- los mitos de Pandora y de Eva se comprenden como discursos fundacionales en los cuales se encriptan una serie de imaginarios y constructos misóginos que son claves en las justificaciones culturales de la inferioridad femenina, del sistema patriarcal y de la legitimación de la violencia hacia las mujeres. Desde esta óptica, este análisis de mitos cosmogónicos aporta a la comprensión de la mantención socio-estructural de las construcciones de género tradicionales $\mathrm{y}$, de paso, permite vislumbrar la persistencia de la violencia de género desde los cimientos de la cultura occidental hasta la actualidad. Como bien se ha señalado, las cosmogonías son mitos fundacionales que conforman el arquetipo de la creación y sirven de modelo al comportamiento humano, ya que en ellos se relata un acontecimiento primordial en el cual "se revela un misterio" (Eliade, 1998; 2000). Dentro de este marco de reflexión, se interconecta lo sagrado con lo divino, por tanto "todo mito muestra cómo ha venido la existencia de una realidad, sea esta la realidad total, el cosmos, o tan solo un fragmento de ella: una isla, una especie vegetal, una institución humana" (Eliade, 1998, p. 73). 


\section{MITOS COSMOGÓNICOS Y PATRIARCADO}

Desde este punto de partida, se comprende cómo el mito contiene la función de control social utilizada especialmente por grupos que detentan el poder, consagrándose -a decir de Martínez Fernández (1996)- como arcano y sagrado, y fijando, también, modelos ejemplares en el campo de la actividad humana, ya sea la alimentación, la sexualidad, el trabajo u otra (Eliade, 1998).

Se puede agregar, en la línea de Tubert (1991), que existen al menos tres rasgos comunes entre los mitos de creación: en ellos, (a) se concibe el origen como un estado de felicidad en el paraíso; (b) posteriormente, se transgrede una prohibición divina, y, por último, (c) el castigo se materializa por medio del trabajo sin descanso, de las penurias y de la enfermedad.

Estas tres dimensiones en la lógica patriarcal de los mitos presentados están estrechamente vinculadas con la diferencia de los géneros, así como con la explicación de las jerarquías sociales. Así, entendemos que en los mitos cosmogónicos se fundan dimensiones relevantes del sistema sexogénero (Rubin, 1986); a través de ellas, todas las sociedades generan ideas y prácticas determinadas para un sexo u otro; en el marco de las sociedades patriarcales, estas ideas y prácticas redundan en la instauración de sistemas estratificados que, a su vez, establecen "rasgos, roles, motivaciones y conductas concebidas como atributos de hombres y de mujeres" (Bosch, Ferrer y Gili, 1999, p. 105). En esta línea, en las culturas patriarcales, los mitos que explican los orígenes de la humanidad son de carácter androcéntrico, tal como se proyecta en la lectura de los mitos donde están presentes Pandora y Eva. Es decir, hacen referencia a la construcción de la realidad y del sujeto desde el punto de vista masculino: así, lo masculino se destaca como lo neutro y universal, mientras que lo femenino se construye como lo nomasculino, como pura otredad (Irigaray, 1992).

Las dimensiones anteriormente comentadas se constituyen en el marco de estructuras de poder determinadas, específicamente, en el sistema patriarcal. Este sistema es entendido como la toma de poder histórica de los hombres sobre las mujeres, que se lleva a cabo sobre la base de un orden biológico elevado a categoría política y económica (Sau, 2017). De ahí que estos elementos sean centrales en el modo de organización patriarcal que se configura como un sistema de poder jerarquizado desde el que se ordenan y proyectan las relaciones de dominación de lo masculino hacia lo femenino en la estructura social (Lerner, 1990; Lagarde, 2001). Por añadidura, en el sistema patriarcal subyace una serie de valores que se reflejan en su 
código sexista y que están presentes en los mitos que protagonizan Pandora y Eva -relatos en los que se definen diversos rasgos implicados en la dicotomía inferioridad / superioridad de los sexos (Alberdi y Matas, 2002). En este sistema, la masculinidad se constituye por sobre la feminidad y, en este sentido, "los componentes centrales a (sic) la masculinidad se hallan no solo el de la negación, sino, también, en la devaluación de todo lo femenino" (Osborne, 2009, p. 43). Del mismo modo, se establece la violencia hacia las mujeres como una suerte de estrategia para asegurar la subsistencia del modelo en el cual la violencia directa no logra ser suficiente para el mantenimiento de la dominación patriarcal (Osborne, 2009).

Tal como presenta Millet en la Política sexual (2010), todas las mitologías de orden patriarcal han postulado la existencia de un orden humano, sin mujeres; una supuesta edad de oro en la cual los hombres viven libres. Así mismo -prosigue la autora-, los mitos de Pandora y Eva se basan en presupuestos morales para validar la misoginia y presentar la supuesta malignidad femenina como antecedente propio de las mujeres, siendo que "la versión mítica de las mujeres como base del sufrimiento humano, del saber y del pecado, condiciona aun hoy en día las actitudes sexuales, por representar el argumento central de la tradición patriarcal de occidente" (Millett, 2010, p. 115).

Consecuentemente, los estudios feministas visualizan la compleja imbricación entre los constructos de género y las múltiples manifestaciones de violencia hacia las mujeres, por lo tanto, evidencian, de paso, cómo este fenómeno opera como un genuino mecanismo de dominación sobre el que se asienta y reproduce el control social dirigido hacia las mujeres (Maqueda, 2006). Todavía más, los estudios guiados por esta perspectiva permiten comprender el peso de los elementos socio-normativos del género para evaluar, a partir de ellos, sus persistencias y posibles transformaciones en el tiempo, así como su relación con la estructura patriarcal y con la violencia de género (Lagarde, 2001).

Por su parte, el mito de Pandora es central en la mitología griega. En este -como se analiza más adelante- se aprecia el discurso sexista que se instala en la construcción de la humanidad. Este nudo problemático es clave para este análisis, si se considera la influencia cultural de la antigua Grecia en Occidente, y el papel de estos relatos como transmisores culturales para naturalizar una ideología misógina en el contexto de sociedades, precisamente, patriarcales (Zaragoza, 2006).

En el caso de Eva, es indiscutible el peso que ostentan los relatos bíblicos en los imaginarios sociales que se han entretejido hasta la actualidad. Tales 
relatos perviven como influencias y pilares de los principios éticos occidentales. Téngase presente que, con la extensión de las religiones monoteístas, se acrecienta el carácter patriarcal de las culturas europeas y occidentales (Alberdi y Matas, 2002). En este sentido, se destaca que la figura de Eva ha sido históricamente analizada en los estudios de género, buscando en ella los rastros de los orígenes del establecimiento de la superioridad masculina en los textos religiosos (Pérez Gil, 1996). De especial importancia es el Génesis que, a su vez, tiene una fuerte vinculación narrativa y simbólica con mitos griegos, fenicios, hititas y sumerios -entre otros-, que, en revisiones monoteístas posteriores, han sido omitidos (Graves \& Patai, 1986).

\section{DIMENSIONES DE LA VIOLENCIA HACIA LAS MUJERES EN PANDORA Y EVA}

Sobre la base de los sucesos que se presentan en la narración del poeta Hesíodo, así como en el Génesis, a continuación, se analizan dos dimensiones simbólicas que alimentan el imaginario femenino sexista que persiste hasta nuestros días: la devaluación femenina y el ser para otro.

El primero de los elementos a considerar es la devaluación femenina. Este punto se evidencia desde el nacimiento/creación de la mujer Pandora, ya que, en esta coyuntura, se establece no solo una naturaleza diferenciada de los sexos-géneros, sino que, también, se enuncia explícitamente la superioridad de lo masculino. Así, en el caso de Pandora, la devaluación femenina se establece únicamente por el hecho de que ella es mujer: es su condición la que permite fundamentar su desigualdad en el código patriarcal, pues esta sería la causa principal que legitima el que ella -en tanto mujer-forme parte de ese otro orden de lo humano (Alberdi y Matas, 2002).

El establecimiento del mismo código patriarcal se observa también en el caso de Eva, cuya narración es central en esta ideología. Aquí se enuncia la posición de las mujeres en la sociedad y es nuclear, en este relato, el hecho de que la primera mujer fuese creada después del primer hombre a partir de una de sus costillas, zanjándose con ello la razón de su dominación ${ }^{4}$. En este sentido, Lerner (1990) destaca que, aunque Adán y Eva deben su creación a Dios, pues, es él quien les dota de vida por medio del aliento divino, ambos fueron creados de manera diferenciada, estableciéndose la superioridad masculina. Mediante este acto diferenciador, queda cerrado el pacto

\footnotetext{
${ }^{4}$ Este argumento es destacado tanto por Lerner (1990) como por Tubert (1991).
} 
dios-hombre que materializa el imperativo de que serán ellos los únicos autorizados para ser mediadores entre lo terreno y lo celestial.

Así, la devaluación femenina sistemática se profundiza cuando se establece que la naturaleza inferior de las mujeres se vincula con los males de la humanidad. De este modo, se concibe que tanto el origen de las mujeres como las dificultades con las que los hombres deben enfrentarse, después de vivir en el paraíso, son parte de un mismo fenómeno. En este sentido, Hesíodo señala en su poema: "Zeus altisonante produjo para los hombres una calamidad, las mujeres, autoras de angustiosas acciones, proporcionándoles, en vez de un bien, este otro mal" (1993, p. 115). En el caso de Pandora, ella es utilizada por Hesíodo para explicar la razón de la existencia del mal en el mundo y, a su vez, para exponer la causa de la inferioridad natural de las mujeres. Lo mismo sucede con Eva, ya que, por su decisión, la primera pareja humana es expulsada del Edén, momento desde el que deben vivenciar una vida terrenal llena de dolor, penurias y sufrimiento.

De este modo, y a partir de ambos mitos, se comprende a las mujeres como seres que proveen problemas, muchas veces incomprensibles para la naturaleza del varón. De ahí que se vislumbren como un encadenamiento ideológico de esta matriz de pensamiento, afirmaciones tales como: "las mujeres son un mal necesario" o "no se puede vivir con ellas ni tampoco sin ellas", asumiendo entonces su naturaleza negativa y problemática. Este punto se vincula con lo planteado por Zaragoza (2006), quien establece que uno de los propósitos de la mitología es establecer las bases patriarcales de la sociedad; y, para ello, se vincula lo femenino con el mal de la humanidad, enlace que legitima la exclusión de las mujeres del dominio de lo racional, acercándolas, por ende, al caos y a la oscuridad.

Es en este marco, que el concepto de violencia simbólica de Bourdieu (2000) es cardinal para la valoración de los mecanismos del mantenimiento del sistema de dominación. Para Bourdieu, los esquemas construidos en las sociedades patriarcales funcionan como matrices de percepción para la comprensión del mundo vivido. De este modo, la visión androcéntrica, tanto de la reproducción biológica como de la social, es investida por una supuesta objetividad de la naturaleza humana. Así, se comprende la realidad desde unos esquemas mentales que son producto de la asimilación de las relaciones de poder -relaciones que, dicho sea de paso, se materializan como parte del "orden natural". Dicho fenómeno tiene como resultado una autodenigración de los grupos dominados que cobra fuerza, especialmente, cuando no se dispone de otro instrumento para conocer y conocerse en el mundo. De esta forma, el efecto de la dominación simbólica: 
No se produce en la lógica pura de las conciencias conocedoras, sino a través de los esquemas de percepción, de apreciación y de acción que constituyen los hábitos y que sustentan, antes que las decisiones de la conciencia y de los controles de la voluntad, una relación de conocimiento profundamente oscura para ella misma. (Bordieu, 2000, pp. 5455)

De manera concordante, la óptica feminista afirma que la violencia hacia las mujeres responde a una relación estructural cuya lógica necesita de la violencia simbólica para subsistir y mantenerse en el tiempo, siendo su horizonte la perpetuación de la dominación sexista. Su carácter estructural es el elemento que provee a la violencia de género sus mayores herramientas para su normalización, naturalización y tolerancia (Osborne, 2009). Por ello, se considera un problema social y no individual (Ferrer \& Bosch, 2000), y, a fin de cuentas, como resultado de la discriminación sustentada en la estructura social y simbólica patriarcal. En este punto, se puede destacar la estrategia de supervivencia propia del orden masculino que, a su vez, "se reproduce por medio de diversas estrategias de (re)creación continuada de las estructuras objetivas y subjetivas de la dominación masculina, de ahí la relevancia de 'reconstruir la historia, del trabajo histórico de deshistorización"” (Bourdieu, 2000, p. 105).

Así, en los mitos analizados, se concibe la existencia de las mujeres solo en relación con lo masculino, como una creación cuyo único objetivo es castigar a la humanidad (sinécdoque de hombres), como se ejemplifica en los casos de Pandora - "trampa, sin salvación y malignamente eficaz" (Hesíodo,1993, p. 46)-, y de Eva -creada a partir de una costilla de Adán.

Como segundo punto, se aprecia que la constitución de lo femenino se realiza bajo la máxima de ser para otro. En este contexto, la llamativa belleza con que fue concebida Pandora no es casual, e implica la consideración del ser-cuerpo femenino como una herramienta para atraer la atención y el deseo masculino. Así, en sus orígenes, Pandora está determinada por los designios de Zeus y, posteriormente, por la respuesta que genera su atractivo físico sobre los hombres, ya sea Prometeo o su hermano Epimeteo. Se debe entender que el de Pandora no es solo un relato que da cuenta de la vida de un personaje; más bien, parece que la pretensión del sujeto que enuncia es la representación de todas las mujeres en tanto género, como una forma de instalar y delimitar la naturaleza de lo femenino, de describir sus características y, sobre la base de esto, de legitimar el lugar devaluado que le corresponde en la sociedad. 
La situación de Eva es similar, pues su creación tiene como propósito que Adán no esté solo, que tenga compañía-ella no es más que un agregado de y para el primer hombre, antecedente de todos los hombres. De este modo, la creación de Eva, en esta narración, no solo sirve para describir el nacimiento de la primera mujer, sino, también, funge como una estrategia que permite explicar la vinculación del origen subordinado con la subyugación a la que deben estar sometidas las mujeres. De acuerdo con esta lógica, Eva es culpabilizada por ser la causante de los problemas humanos; es por sus acciones, por su supuesta soberbia y por su desobediencia, que los hombres conocen el pudor y el dolor. Se enfatiza, a través de los siglos, que es ella quien toma el fruto prohibido y que es por esta razón que el hombre padece el castigo divino.

De este modo, su presencia logra explicar los castigos humanos, señalándola, tal como describe Molina Petit (2003), como la "instigadora al mal, la tentadora, la primera culpable" (p. 48). Es por ella que Adán y su descendencia serán condenados; con ello, se designa a Eva como aquella que provoca la maldición para la humanidad y se la asocia, entonces, al pecado y a la destrucción de la vida en el paraíso (Alberdi y Matas, 2002).

En esta línea, es relevante considerar que tanto Pandora como Eva no nacen de mujeres. En el caso de la primera, es modelada/creada por Hermes, nace de un varón al igual que Atenea, quien proviene de la cabeza de Zeus 5 . En el caso de la segunda, tal como observa Lerner (1990), también se cancela la imagen femenina materna para sustituirla por la del varón que da la vida. Todo esto no es más que una metáfora que sirve para organizar un parentesco que no se refleja en la realidad; por defecto, tanto la procreación como el linaje son actos masculinos que permiten la prescindencia de las madres. Así, y en la línea de Rivera Garretas (1994), se puede observar un claro matricidio, requisito necesario para la conformación y para la cimentación del patriarcado como consecuente anulación de la genealogía femenina ${ }^{6}$.

\footnotetext{
${ }^{5}$ Atenea destaca por su inteligencia, la que al parecer, como característica reservada para el sujeto/varón, anularía una de las particularidades femeninas más definitorias desde el patriarcado, como lo es su capacidad de reproducción, pues ella es infértil. Posteriormente, tal como señala Lerner (1990), la propia Atenea realizará el pacto con el patriarcado, pues defiende a Orestes del asesinato materno ante las Furias, al argumentar que ella no nació de mujer y que, por tanto, le debe lealtad al padre, estableciéndose así el principio paterno y la valoración de la mujer como un cuerpo cuyo papel es simplemente incubar la semilla del varón.

${ }^{6}$ En esta misma línea, Sau (2017) da cuenta de la práctica Couvade presente en diversos momentos históricos y culturas, en la que cuando una mujer daba a luz, el padre de la criatura emulaba el parto con supuestos dolores y gemidos, y posteriormente recibía los cuidados vinculados al parto y puerperio. Para la autora, este acto se llevaba a cabo para la constitución simbólica de la
} 
De este modo, se aprecia cómo, en ambos casos, se responsabiliza a las mujeres por la infelicidad y, además, con el dato genealógico que enfatiza que ellas "nacen de un hombre", se las subyuga simbólicamente al poder masculino y se rescinden otras cosmogonías que sí dan cuenta del poder de las diosas creadoras?.

Sobre esta base, se destaca que estos mitos patriarcales del origen de la humanidad han calado profundamente en el imaginario de la cultura occidental y constituyen una instancia de legitimación discursiva del patriarcado que, para mantenerse, debe procurar(se) discursos en los cuales se valide estatus diferenciados entre hombres y mujeres.

De acuerdo con el análisis de estos mitos, se presencia dicha validación en la misoginia, en el sexismo y en la violencia infligida en contra de las mujeres, por lo cual, a partir de los puntos señalados, se entiende que dicha dimensión de la tradición mítica ha devenido históricamente en herramienta subjetiva de control y de legitimación en la medida en que justifica las desigualdades y -mediante el mito- las juzga como naturales.

Estas instancias discursivas logran pasar desapercibidas en tanto dispositivos de modelación y coerción social, ya que son tomadas por las audiencias como historias de la historia. La complejidad de este asunto radica, precisamente, en ese mismo punto, pues en la construcción de las identidades y de los roles de género vigentes en la actualidad aún emergen tales planteamientos relativos a lo femenino y a lo masculino.

\section{REFLEXIONES FINALES}

De acuerdo con Montecino (1997), se puede aseverar que los mitos reflejan los sentidos, las representaciones y las valoraciones de las distintas sociedades. Quizá, por lo mismo, las construcciones de género, como productos culturales, están siempre presentes en dichos imaginarios y -por tanto"los relatos míticos parecen ser espacios estratégicos para conocer el universo de las representaciones en torno al género en las distintas comunidades humanas" (p. 67).

superioridad de la paternidad por sobre la maternidad, así como la cancelación del poder de las mujeres en sociedades patriarcales y patrilineales.

${ }^{7}$ Por ejemplo, Eisler, en su libro El cáliz y la espada (2003), destaca la presencia transversal del culto prehistórico a la diosa, situación que según la autora se puede comprender por la veneración de la deidad en todas las antiguas sociedades agrícolas y la presencia de su culto en el arte del neolítico. 
De este modo, en el análisis realizado, se han podido establecer dos elementos centrales que reproducen la violencia hacia las mujeres: la devaluación de lo femenino y el ser para otro. Estos elementos son bases fundamentales de dominación masculina, ya que autorizan y/o justifican construcciones de género desiguales, tratos diferenciados a mujeres $\mathrm{y}$ a varones, $\mathrm{y}$-por añadidura- sustentan códigos de violencia permitidos e invisibilizados por la sociedad. Se afirma, entonces, que la integración de estos elementos en la(s) identidad(es) femenina(s) constituye un tipo particular de violencia simbólica, por cuanto el imaginario de feminidad es de por sí devaluado tanto por los hombres como por las propias mujeres que reproducen discursos sexistas naturalizados; especialmente, si se tiene en cuenta el poder simbólico tanto de la mitología griega como de la religión judeo-cristiana en la cultura occidental. En la mitología y en la religión en que se inscriben los mitos de Pandora y de Eva existe una constante referencia a la dominación masculina (Alberdi y Matas, 2002).

En la actualidad se observa cómo la violencia simbólica hacia las mujeres se valida a través de distintos medios, por ejemplo, en la reproducción acrítica de estas narraciones míticas que, hoy, circulan y se absorben sin mayores cuestionamientos a sus argumentos o a las relaciones de poder que legitiman. Así, el sistema de dominación patriarcal no solo se reproduce, sino que también se naturaliza.

En esta línea, la reflexión presentada permite analizar y confrontar estos grandes mitos fundacionales desde una mirada crítica feminista en torno a los mecanismos de poder proyectados. En distintos espacios y formatos, estos relatos -y sus versiones contemporáneas- influyen directa y silenciosamente en las identidades y relaciones de género actuales. Por ello, es importante volver sobre lo que planteó Bourdieu (2000) en cuanto a la violencia simbólica: esta no podrá ser cuestionada si es que no se generan nuevas formas de pensamiento/conocimiento que permitan entrever la realidad más allá de las matrices de percepción patriarcal. Si tanto mujeres como varones siguen encontrándose como sujetos sociales en textos y narraciones que, desde posiciones patriarcales, instalan y explican naturalezas diferenciadas entre lo masculino y lo femenino, parece difícil que se cuestionen otros tipos de violencias cotidianas que vivencian las mujeres y que, todavía, se entienden como "parte del orden de las cosas".

Es, en este sentido, interesante considerar lo que plantea Eliade (1998), en cuanto a que el/la sujeto de la modernidad, le guste o no, "conserva huellas del comportamiento religioso, pero expurgadas de sus significados religiosos" (p. 149). Consecuentemente, se entiende que una lectura 
feminista expulsa los mitos cosmogónicos o fundacionales de las funciones políticas primarias que desempeñan en su contexto cultural y cuestiona su trasmisión acrítica hacia la cultura occidental. Con ello, consigue impugnar la misoginia y la violencia simbólica dirigida hacia las mujeres que se inscriben en estos discursos y, al fin, devela las relaciones de poder que se justifican y legitiman a partir de ellos. Con todo, el objetivo de este tipo de lecturas es promover una actitud reflexiva en torno a dichos mecanismos y al papel que desempeñan en la construcción, tanto de la sociedad presente como de aquella que vislumbramos hacia el futuro. En virtud de ello, es importante atender a la peculiaridad de determinadas instituciones en sociedades occidentales y -quiérase o no-, esto supone "interrogarse sobre las características que llevan al establecimiento y la conservación de dichas instituciones; para de este modo investigar cómo estructuran la vida, cómo abren posibilidades e imponen limitaciones" (Wagner, 1997, p. 63).

\section{REFERENCIAS}

Alberdi, I. y Matas, N. (2002). La violencia doméstica: Informe sobre malos tratos a mujeres en España. Barcelona: Fundación La Caixa. Disponible en: http://bit.ly/2FooGeJ

Biblia (1968). Barcelona: Alpha, DL, Fundación Bíblica Catalana. Institut Cambó.

Bosch, E. y Ferrer, V. (2003). Maltrato de mujeres y misoginia: Estudio empírico sobre un posible factor explicativo. Anuario de Psicología 34(2), 215-233.

Bosch, E., Ferrer V., y Gili, M. (1999). Historia de la misoginia. Barcelona: Editorial Anthrophos.

Bourdieu, P. (2000). La dominación masculina. Barcelona: Editorial Anagrama. Eisler, R. (2003). El cáliz y la espada: La mujer como fuerza en la historia. Santiago de Chile: Editorial Cuatro Vientos.

Eliade, M. (1998). Lo sagrado y lo profano. Barcelona: Editorial Paidós.

Eliade, M. (2000). Aspectos del mito. Barcelona: Editorial Paidós.

Ferrer, V. y Bosch, E. (2000). Violencia de género y misoginia: Reflexiones psicosociales sobre un posible factor explicativo. Papeles del Psicólogo (75), 13-19. Disponible en: http://bit.ly/2DEz1mc

Graves, R. (1967). Los mitos griegos. Buenos Aires: Editorial Losada.

Graves, R. y Patai, R. (1986). Los mitos hebreos. Madrid: Alianza Editorial.

Hesíodo (1993). Los trabajos y los días, Teogonía y el Escudo de Heracles. España: Editorial Iberia.

Irigaray, L. (1992). Tú, yo, nosotras. Madrid: Editorial Cátedra.

Lagarde, M. (1997). Cautiverios de las mujeres: Madresposas, monjas, putas, presas y locas. México: Universidad Nacional Autónoma de México. 
Lagarde, M. (2001). Género y feminismo. Desarrollo humano y democracia. España: Editorial Cuarto Propio.

Lerner, G. (1990). La creación del patriarcado. Barcelona: Editorial Crítica.

Maqueda, L. (2006). Violencia de género. Entre el concepto jurídico y la realidad social. Revista Electrónica de Ciencia Penal y Criminología. Disponible En: http://criminet.ugr.es/recpc/08/recpc08-02.pdf

Martínez Fernández, P. (1996). Los mitos: Manipuladores ideológicos. Puerto Rico: Editorial Borikén Libros.

Millett, K. (2010). Política sexual. Madrid: Ediciones Cátedra.

Molas Font, M. (2006). La violencia contra las mujeres en la poesía griega: de Homero a Eurípides. En M. Molas Font (Ed.), La violencia de género en la antigüedad (pp. 32-62). Madrid: Instituto de la Mujer. Disponible en: http:// bit.ly/2DJNxOf

Molina Petit, C. (2003). Género y poder desde sus metáforas. Apuntes para una topografía del patriarcado. En S. Tubert (Ed.), Del sexo al género (pp. 123160). Madrid: Ediciones Cátedra.

Montecino, S. (1997). Palabra dicha. Escritos sobre género, identidades, mestizajes. Santiago: Universidad de Chile. Colección de Libros Electrónicos.

Nácar Fuster, E., y Colunga, A. (1968). Sagrada Biblia: Versión directa de las lenguas originales, hebrea y griega, al castellano. España: Editorial de Biblioteca de Autores Cristianos.

Osborne, R. (2009). Apuntes sobre violencia de género. Barcelona: Editorial Bellaterra.

Pérez Gil, M. (1996). El mito de Eva en la literatura feminista reciente. Actas de Congreso XIXth International Conference of AEDEAN, 463-469. Disponible en: http://hdl.handle.net/10553/25154

Rivera Garretas, M. (1994). Nombrar el mundo en femenino. Barcelona: Icaria Editorial.

Rubin, G. (1986). El tráfico de mujeres: Notas sobre la “economía política” del sexo. Revista Nueva Antropología, 8(30): 95-145. Disponible en: http://bit. ly/2nkwAOD

Sau, V. (2017). Diccionario ideológico feminista. Barcelona: Icaria Editorial.

Trujillo, M. y Almeda, E. (2017). Monomarentalidad e imaginarios de género en contexto migratorio: Punto de vista epistemológico feminista en el estudio de las migraciones. Revista Empiria (37), 101-125. Disponible en: // https://doi.org/10.5944/empiria.37.2017.18978

Tubert, S. (1991). Mujeres sin sombra: Maternidad y tecnología. Madrid: Siglo Veintiuno Editores.

Wagner, P. (1997). Sociología de la modernidad. Barcelona: Herder Editorial.

Zaragoza, J. (2006). Violencia y misoginia. Los Raptos. En M. Molas Font (Ed.), La violencia de género en la antigüedad (pp. 63-76). Madrid: Instituto de la Mujer. Disponible en: http://bit.ly/2DJNx0f 